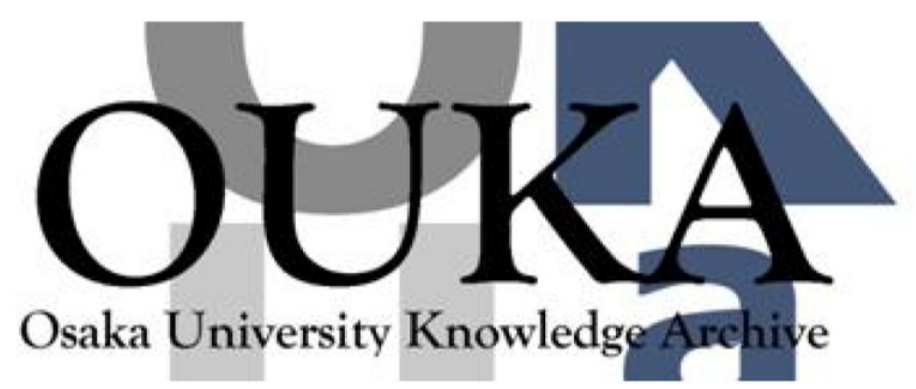

\begin{tabular}{|c|c|}
\hline Title & A framework of eco-design support \\
\hline Author(s) & $\begin{array}{l}\text { Kobayashi, Hideki; Hongu, Akinori; Haruki, } \\
\text { Kazuhito et al. }\end{array}$ \\
\hline Citation & $\begin{array}{l}\text { Proceedings First International Symposium on } \\
\text { Environmentally Conscious, Design and Inverse } \\
\text { Manufacturing (EcoDesign, 99). p. 680-p.684 }\end{array}$ \\
\hline Issue Date & 1999 \\
\hline oaire:version & AM \\
\hline URL & https://hdl. handle. net/11094/85128 \\
\hline rights & $\begin{array}{l}\text { (1999 IEEE. Personal use of this material is } \\
\text { permitted. Permission from IEEE must be } \\
\text { obtained for all other uses, in any current or } \\
\text { future media, including reprinting/republishing } \\
\text { this material for advertising or promotional } \\
\text { purposes, creating new collective works, for } \\
\text { resale or redistribution to servers or lists, } \\
\text { or reuse of any copyrighted component of this } \\
\text { work in other works. }\end{array}$ \\
\hline Note & \\
\hline
\end{tabular}

Osaka University Knowledge Archive : OUKA

https://ir. Library. osaka-u. ac. jp/

Osaka University 


\title{
A Framework of Eco-design Support
}

\author{
Hideki Kobayashi, Akinori Hongu, Kazuhito Haruki, Seizo Doi \\ Environmental Engineering Lab., R \& D Center, Toshiba Corp. \\ 8 Shinsugita-cho, Isogo-ku, Yokohama, Kanagawa 235-8522, Japan
}

\begin{abstract}
Although there are several methods and tools to support environmentally-conscious design (eco-design) from various viewpoints, the images of integrated design support systems are few. In this paper, a framework of an eco-design support is proposed to make an integrated system image clear, as followings. 1) Requirements of eco-design support are clarified. 2) Environmental targets are derived. 3) A configuration of an eco-design support system which consists of tools is described. 4) Relations between tools and design processes are described. In addition, the recyclability evaluation tool which is newly implemented in the system is described.
\end{abstract}

\section{Introduction}

Environmental issues are so important that the manufacturing industry must consider them. A product that simultaneously satisfies the cost-performance target and the environmental target throughout the entire product life cycle is called an environmentally-conscious product (ECP). Designing an ECP involves designing not only the product but also the product life cycle process from the material acquisition phase to the disposal phase. Hence, design of ECPs is also called life cycle design [1,2]. In this paper, a framework of environmentally-conscious design (eco-design) support system and a tool recently implemented in the system are described.

Several eco-design support methods and the tools have been reported from various viewpoints [e.g. 3, 4]. Currently, life cycle assessment (LCA) and design for disassembly (DFD) are the main areas of research. However, there are few concepts of the framework which integrates tools as an eco-design support system. In this paper, at first, some requirements of eco-design support are clarified. Second, environmental targets are clarified. Third, the configuration of an eco-design support system which consists of tools is described. Fourth, relations between tools and design processes are described. In addition, as an example of tools, a recyclability evaluation tool which has been implemented in the system is described.

\section{A framework of eco-design support}

\subsection{Requirements of eco-design support}

There are the following problems which eco-design support researches should solve.

- $\quad$ Each design support tool has been developed from a particular viewpoint. Hence, eco-design support tools suitable for practical applications must be selected one by one.

- A designer must treat too much information, and therefore the designer's workload is greatly increased.

- Although it is necessary to consider the product, its life cycle and the business strategy, a holistic design methodology is not systematized yet.

- A designer may be confused because each design support tools can be used without process management.

- It is difficult to achieve a balance between cost-performance and environment targets in a design project, and to attain the targets.

- The upstream design phases such as conceptual design which greatly influence a design solution are not supportable.

- Many tools are not practical for the designer.

Some of these issues are also being addressed in intelligent computer aided design (CAD) research. To deal with these problems, the eco-design support system should take account of the following requirements.

- Clarify environmental targets and select design support tools corresponding to them.

- Minimize overlaps of data to be easily shared with and managed by many tools.

- Take into consideration the product's life cycle process and business strategy from an environmental viewpoint in the early phase of the design.

- $\quad$ Take into consideration of design process.

- Develop a method of balancing targets, and always refer to an overall conception.

- Support designers throughout the entire design phase. 


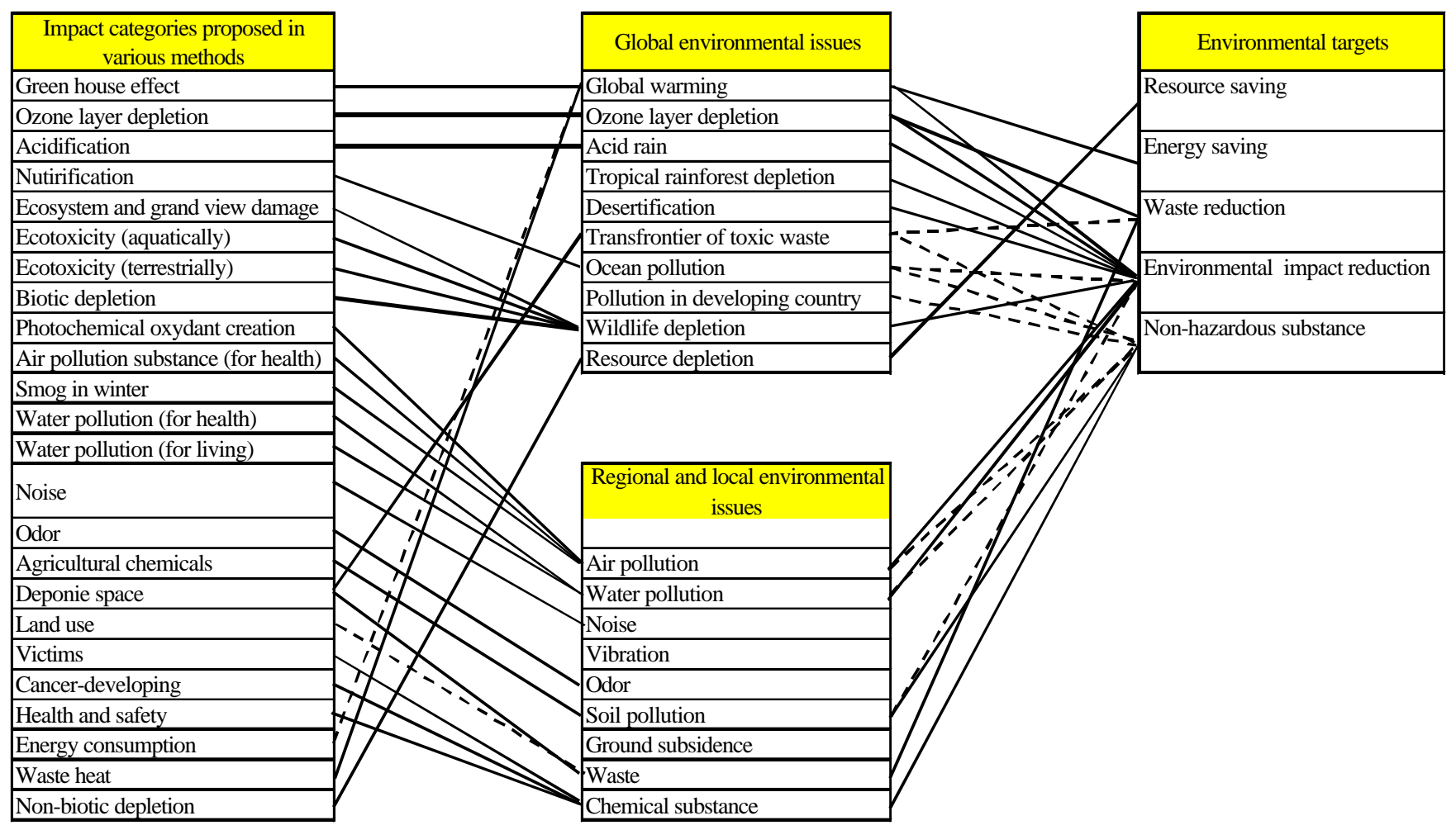

Figure 1: Environmental issues and comprehensive targets

- Develop tools from the viewpoint of simplicity and easy of use.

A framework of eco-design support which satisfies these requirements must be specified.

\subsection{Clarification of environmental targets}

The environmental issues consist of global and regional / local issues and the relations among these issues are complicated. For fruitful discussion of the environmental consciousness of an industrial product, therefore, it is necessary to clarification of environmental targets comprehensively. In this paper, based on the analysis of various environmental issues (Fig. 1), we define five targets, i.e., "resource saving, energy saving, waste reduction, environmental impact reduction, and non-hazardous substance".

\subsection{Environmental targets and tools}

The system configuration for eco-design support is proposed in Fig. 2. The system is classified into 4 categories: the tools for attaining the environmental and cost-performance targets, and the tools for making decision and information management.

A product life cycle planning (LCP) tool is for making the business strategy and the concept of a product and its life cycle process. To realize high environmental consciousness, it is necessary to consider the product and the business simultaneously. An LCA tool is for evaluating environmental impact. The standardization of LCA is now progressing in the ISO14000 series. Toshiba has already developed and commercialized an LCA tool [5]. A group of design for reuse and recycling (DFR) tools contains a reusability and a recyclability evaluation tool, a

The tools for attaining environmental targets

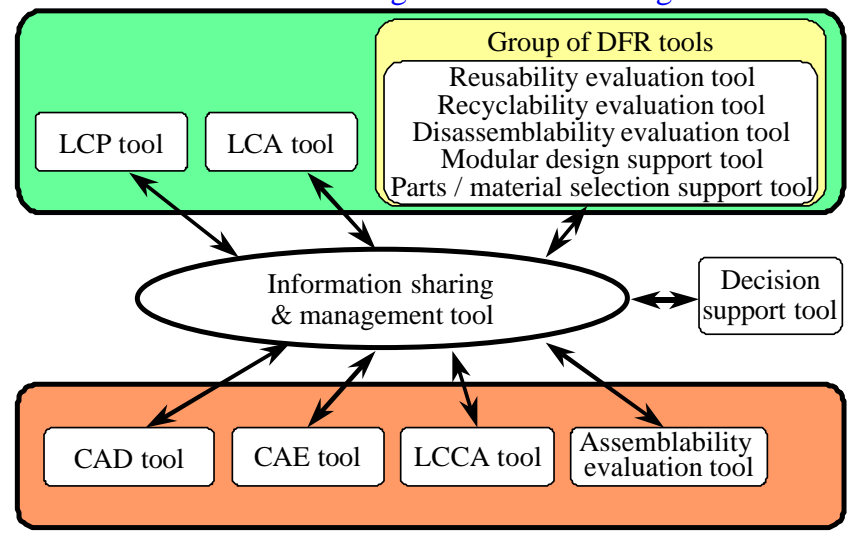

The tools for attaining cost-performance targets

Figure 2: The system configuration 
disassemblability evaluation tool [6], a modular design support tool, and a parts / material selection support tool. Here, a modular design support tool is for ease of upgrade, reuse or recycling.

Design support tools which are developed in order to attain cost-performance targets, for example a computer aided design (CAD) tool i.e., a structure-making tool in this context, a computer aided engineering (CAE) tool, i.e., a simulation tool in this context, an assemblability evaluation tool and so on, are incorporated into this eco-design support system. Although a tool for energy-saving design is important, its function is included of a CAE tool. Further, a life cycle cost assessment (LCCA) tool is required. An LCCA tool is for computing such cost throughout the entire product life cycle, and especially for evaluating competitiveness in the designing a reuse- or recycling-oriented product.

A decision support tool for selecting design alternatives, and an information sharing \& management tool are important subsystems, too. In particular, the latter is useful for minimizing data overlap and decreasing the designer's workload. Moreover, in order to integrate multiple models at a logical or semantic level, information sharing is important [7].

Table 1: The relations between environmental targets and support tools

\begin{tabular}{|c|c|c|c|c|c|}
\hline & 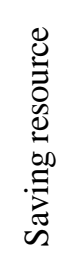 & 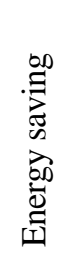 & $\begin{array}{l}0 \\
.0 \\
0 \\
0 \\
0 \\
0 \\
0 \\
0 \\
0 \\
3\end{array}$ & 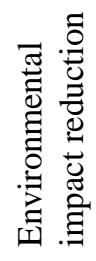 & 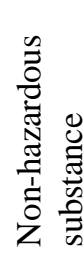 \\
\hline LCP tool & ++ & ++ & ++ & + & + \\
\hline LCA tool & + & ++ & + & ++ & $\mathrm{x}$ \\
\hline $\begin{array}{l}\text { Reusability } \\
\text { evaluation tool }\end{array}$ & ++ & + & + & $\mathrm{x}$ & $\mathrm{x}$ \\
\hline $\begin{array}{l}\text { Recyclability } \\
\text { evaluation tool }\end{array}$ & ++ & + & ++ & $\mathrm{x}$ & $\mathrm{x}$ \\
\hline $\begin{array}{l}\text { Disassemblability } \\
\text { evaluation tool }\end{array}$ & + & $\mathrm{x}$ & ++ & $\mathrm{x}$ & + \\
\hline $\begin{array}{l}\text { Modular design } \\
\text { support tool }\end{array}$ & ++ & $\mathrm{x}$ & + & $\mathrm{x}$ & $\mathrm{x}$ \\
\hline $\begin{array}{l}\text { Parts / material } \\
\text { selection support } \\
\text { tool }\end{array}$ & + & + & $\mathrm{x}$ & + & ++ \\
\hline
\end{tabular}

++: strongly supported, +: supported, x: not supported
The relation between the environmental targets and the design support tools is shown in Table 1. Here, environmental targets can be comprehensively covered by the tools. We consider that the fewer the kinds of tools, the more practical a design support system is. Thus, the proposed system configuration is considered to satisfy the necessary conditions for supporting an eco-design.

\subsection{Tools and design process}

From a designer's practical viewpoint, it is necessary to apply each tool for the appropriate design phase and designer's problem solving process. A design process can be considered to consist of planning, conceptual design, embodiment design, and detailed design phases. Further, in each design phase, a problem solving cycle exists; which consists of awareness of problem, suggestion, development, evaluation, and decision processes. Here, the dominant thought process in each design phase is considered to be as follows:

- Planning: awareness of problem

- Conceptual design: suggestion

- Embodiment design: development and evaluation (trial and error process)

- Detailed design: development and evaluation (optimization process)

For example, in the spiral representation of the design process, the relations between the tools and design process is shown in Fig. 3. Each tool supports the dominant thought process in each design phase, and therefore, we consider the proposed system to be useful.

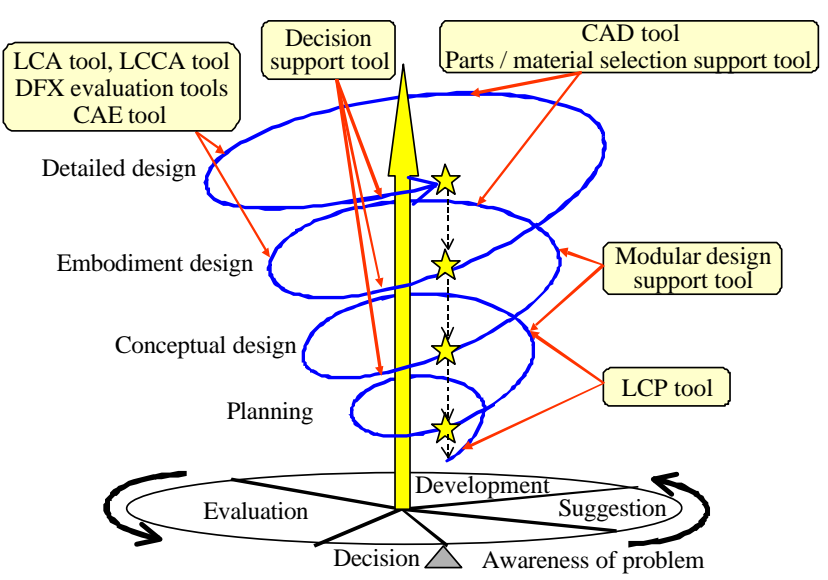

Figure 3: Design spiral and design support tools 


\section{A recyclability evaluation method}

\subsection{Measurement}

In this chapter, a recyclability evaluation method and its tool are presented. Some ideas of respecting recyclability evaluation have been reported [e.g. 8,9].

(a) Degree of unification of the kind of material included in a product

(b) Degree of material distribution

(c) Modularization of product for recycling

(d) Ratio of recyclable material

(e) Separability of different material

(f) Disassemblability

(g) Recognizability of hazardous substance

We propose a method of evaluating product recyclability based on (a) to (d) above, since (e) is a factor which will be improved by the time of product retirement, (f) is treated by the disassemblability evaluation tool, and importance of $(\mathrm{g})$ is reduced by non-use of hazardous substances from the initial design phase onward.

Here, a measure $\mathrm{S} 1$ respecting (a) can be formulated by

$$
S 1=-\sum_{i=1}^{l} \frac{w_{i}}{w} \log \frac{w_{i}}{w}
$$

where $\quad w=\sum_{i=1}^{l} w_{i}, w:$ total weight

and $w_{i}: i$ th material's weight $(i=1,2, \Lambda, l)$.

The value of $\mathrm{S} 1$ decreases as the number of kinds of material decreases or the material existence ratio becomes unity.

Likewise, a measure $\mathrm{S} 2$ respecting (a) to (c) can also be formulated by

$$
\begin{aligned}
& S 2=-\sum_{j=1}^{m} \sum_{i=1}^{l} \frac{w_{i j}}{w_{j}} \log \frac{w_{i j}}{w_{j}}, \\
& \text { where } w_{j}=\sum_{i=1}^{l} w_{i j}, w=\sum_{j=1}^{m} w_{j} \\
& \text { and } w_{j}: j \text { th module's weight }(j=1,2, \Lambda, m) .
\end{aligned}
$$

The value of $\mathrm{S} 2$ is not based on the size of the module, and decreases as the number of kinds of material decreases or the material existence ratio becomes unity, for every product module level.

The product recyclability becomes high as the values of
$\mathrm{S} 1$ and S2 become low. However, there is obviously a difference between $\mathrm{S} 1$ and $\mathrm{S} 2$, in the case of the application to the virtual product shown in Fig. 4. In this figure, both product $\mathrm{A}$ and $\mathrm{B}$ consist of three modules. Here, each module included in product $\mathrm{A}$ has the same material organization. Each module included the product $\mathrm{B}$ consists of a single material and different materials are used for every module.

\section{Product A}

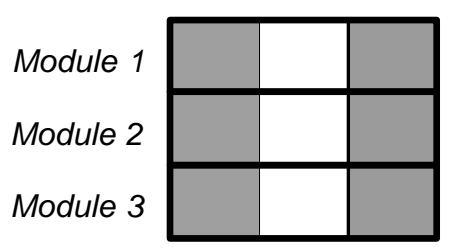

Material $1 \square$ Material 2
Product B

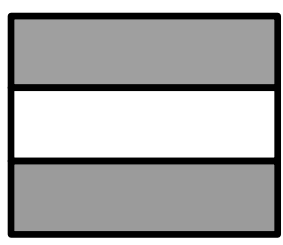

Material 3
Figure 4: Two products made of three materials

Product B has higher recyclability than product A, since each module can be easily processed in the material recycling process. The superiority of the product $\mathrm{B}$ can be evaluated by the measure S2 (Table 2). However, the difference between products A and B cannot be evaluated by the measure S1 (Table 2). Therefore, we adopt the measure S2 as a primitive element of recyclability evaluation.

Table 2: Comparison of the evaluation results

\begin{tabular}{|c|c|c|}
\hline Measurement & Product A & Product B \\
\hline S1 & 0.48 & 0.48 \\
\hline S2 & 1.43 & 0.0 \\
\hline
\end{tabular}

Meanwhile, the recyclable material ratio R1 evaluating the above idea $(\mathrm{d})$ is given by

$$
R 1=\frac{\sum_{k=1}^{n} w_{k}}{w},
$$

where $w_{k}: k$ th recyclablematerial's weight $(k=1,2, \Lambda, n$ and $n \leq l)$.

The product recyclability becomes high as the value of R1 becomes high. Incidentally, an evaluation result differs greatly depending on what materials are considered to be recyclable. For example, iron, copper, aluminum, paper, 
glass, polyethylene (PE), polypropylene (PP), polyester (PS), and acrylonitrile-butadiene-styrene copolymer (ABS) can be considered to be a recyclable materials.

We consider that the comprehensive evaluation from the viewpoints (a) to (d) can be carried out by mapping an object on the plane around the axes of S2 and R1.

\subsection{Implementation}

The evaluation method based on the measures of S2 and R1 is implemented on Microsoft Windows PC. Figure 5 illustrates an evaluation example by the tool. This tool is easy to use because the data input workload is reduced by the data available from CAD. With regard to evaluating the usefulness of this tool, some case studies are in progress.

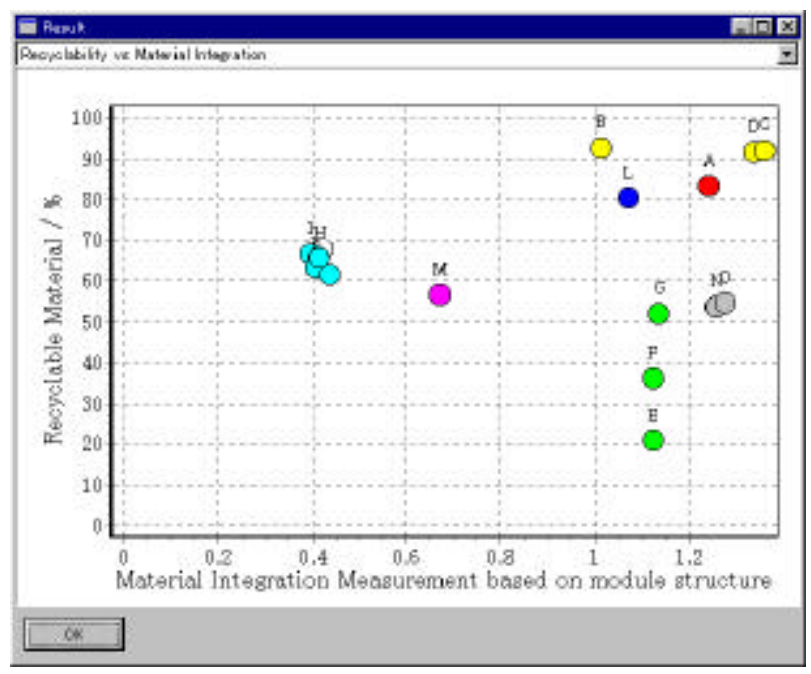

Figure 5: An evaluation example

\section{Summary}

The results of this paper can be summarized as follows:

- The requirements of eco-design support were clarified.

- Environmental targets were derived.

- The configuration of the eco-design support system was proposed.

- The relationship between the tools and design process was described.

- The recyclability evaluation method was proposed, and the design support tool to implement this method was developed.

As we have been developing an eco-design support system based on the proposed framework, we intend to present the system with some case studies in the near future.

\section{References}

[1] Alting, L. and Legarth, B., Life Cycle Engineering and Design, Annals of the CIRP, 44-2, 1995, pp1-11.

[2] Ishii, K., Life Cycle Engineering Design, Trans. of the ASME, 117, 1995, pp42-47.

[3] Krause, F. L. and Jansen, H.(eds.), Life Cycle Modelling for Innovative Products and Processes, Chapman \& Hall, London, 1995

[4] Krause, F.-L. and Seliger, G.(eds.), Life Cycle Networks, Chapman \& Hall, London , 1997

[5] Takeyama, N and Kagami, H., application of Simplified Estimation Method of Life Cycle Assessment to Office-automation Products, Proc. of the second Int. Conf. on EcoBalance, 1996, pp216-221.

[6] Taniuchi, H., Suguro, T, and Matsuyama, H., Asembability and Disassemblability of Notebook Type Personal Computer, IE Review, 38-4, 1997, pp21-27, (in Japanese)

[7] Kurakawa, K., Kiriyama, T., Baba, Y, Umeda, Y, and Kobayashi, H., The Green Browser: An Internet-based Information Sharing Tool for Product Life Cycle Design, in [4], pp454-466.

[8] Beitz, W., Design for Ease of Recycling, in [3], pp489-500.

[9] Meerkamm, H. and Weber, J., Design for Recyclability - an Analysis - Tool in the "Engineering Workbench", in [3], pp501-512. 